\title{
Natural Dye Sources and its Applications in Textiles: A Brief Review
}

\author{
Lizamoni Chungkrang* and Smita Bhuyan \\ Department of Textiles and Apparel Designing, College of Community Science \\ Assam Agricultural University, Jorhat-785013, Assam, India \\ *Corresponding author
}

\section{A B S T R A C T}

\section{Keywords}

Dyes, Synthetic, Natural, Natural fibre etc

\section{Article Info}

Accepted: 07 September 2020 Available Online: 10 October 2020
Presently there is a great demand for the use of natural colours throughout the world due to non-biodegradable and carcinogenic nature associated with synthetic dyes. Natural dyes are non-toxic, non-allergic and non-carcinogenic as these are obtained from animals or vegetable matters without any chemical processing. Natural dyes are mostly used to dye natural fibers like cotton, wool and silk. The colours produced by natural dyes are soothing to eyes, earthly, warm and highly appealing. This article attempts to reviews the available natural dye sources, applications and comparison between the natural and synthetic dyes have been also discussed.

\section{Introduction}

Colour has always played a dominant role in human life since time immemorial. In every civilization from Stone Age to the 'Silicon slip age', it has played an important role in adding beauty to the world (Bhuyan and Saikia, 2004). Our lives, the clothes we wear, the furnishings of our homes strongly influenced by colour (Yusuf et al., 2017). Dyes are the colourant matters which penetrate into the fibre and appear to become a part of it. Dyes may be either natural or synthetic and both these dyes are used for dyeing fibres, yarns and fabrics (Kajla and Srivastava, 2006). Presently there is a great demand for the use of natural colours throughout the world. All this happened due to the excessive use of synthetic dyes which is estimated around 10, 00,000 tones per annum (Gulrajani, 1999). Synthetic compounds are used for dyeing textile materials and they cause water pollution as well as waste disposal problems because these are nonbiodegradable and carcinogenic. To get rid of this environmental as well as health hazards it is essential to think about alternative of synthetic dyes which can make safe environment and human health. To this view point natural dyes could be a good solution for textile sector. There are many natural dyes available in different plants and vegetables in the Universe which may be used as supplementary of synthetic dyes (Guha, 2019; Islam et al., 2014). Another alternative which has fascinated many users is the use of natural 
dyes, i.e., those colourants which can be extracted out of vegetables or animal sources are in general considered to be eco-friendly in nature (Kajla and Srivastava, 2006).

Most of natural dyes have low affinity for textiles (cotton, wool and silk) and require the use of mordant. The word "Mordant" has been derived from latin word "modere" meaning "to bite" (Prabhu and Bhute, 2012). Mordants are generally metallic salts of aluminum, iron, chromium, copper and others, for ensuring the reasonable fastness of the colour to sunlight and washing (Geelani et al., 2016; Chungkrang et al., 2018). The mordant is known as the element which can facilitate the chemical reaction taking place between the textile fibre and the dye or pigment; as a result, the dye is absorbed into the textile material (Singh and Srivastava, 2015; Vankar et al., 2009).

Natural dyestuff can produce a wide range of colours by mix and match system. A small variation in the dyeing technique or the use of different mordants with the same dye can shift the colours of a wide range or create totally new colours, which are not easily possible with synthetic dyestuffs (Tasneem and Maria, 2016).

For successful commercial use of natural dyes, the appropriate and standardized dyeing techniques need to be adopted without scarifying required quality of dyed textiles materials. Therefore, to obtain newer shades with acceptable colour fastness behavior and reproducible colour yield, appropriate scientific techniques or procedures need to be derived from scientific studies on dyeing methods, dyeing process variables, dyeing kinetics and compatibility of selective natural dyes. A need has also been felt to reinvestigate and rebuild the traditional processes of natural dyeing to control each treatment (preparation, mordanting) and dyeing process variables for producing uncommon shades with balanced colour fastness and eco-performing textiles (Tripathi et al., 2015; Samanta and Agarwal, 2009).

Comparison between the natural and synthetic dye

As compared to synthetic dyes the natural dyes are costlier because they cannot be produced in large quantities. However, the application process of natural dyes is less costly. It should also be noted that natural dyes have higher tinctorial value (Sengupta, 2001; Tekajev, 2003). They produce a wide range of excellent lustrous, gentle, soft and biodegradable colours with the use of different mordants. All natural dyes based on the vegetable origin are renewable (Chavan, 1995; Paul et al., 1996 and Gupta, 1990).

Making consumers aware of the environmental problems caused by synthetically dyed textiles and making on alternative widely available are the keys to the success of natural dyes. Developing countries figure prominently in this equation because their lower labour costs will help to offset the higher cost of the natural dyeing process. In addition, many developing countries already have long traditions of natural dyeing and possess the raw materials to extract dyes. Natural-dyed products thus represent a good opportunity for value-added exports from countries that already are world leaders in textile manufacturing (Gulrajani, 2001; Mukherjee et al., 2005; Sankar et al., 2005; Singh et al., 2001).

Natural dyes are the safe dyes, because they do not produce any undesired by-products and at the same time they help in regenerating the environment (Akkewar, 1999; Darwekar et al.1999). In spite of these several advantages, natural dyes have over synthesis; their use is still limited due to the non availability of dyes 
in the standardized farm, shortage of trained dyers, knowledge gap, higher labour cost associated with collection and preparation of dyes (Gulrajani, 1999). But many natural resources that are being wasted indiscriminately or go away as waste products contain useful pigments. The eco-friendly nature of natural dyes produces fantastic, attractive, earthy colours (Gowda and Sudhakar, 2001; Kerolia and Dilliwar, 2004).

\section{Sources of natural dyes}

Natural dyes have better biodegradability and generally higher compatibility with the environment. They are non-toxic, non-allergic and non-carcinogenic as these are obtained from animals or vegetable matters without chemical processing (Pruthi et al., 2008). Natural dyes are multi component extracts of unknown concentrations out of which structure of only main component is determined (Singh and Parmer, 1998; Khan et al., 2005).

The main source of natural dyes are vegetables, animals and minerals (Rose et al., 2005; Bansal and Sood, 2006; Phukan et al., 2005). Natural dyes are colourants which can be derived from plants, minerals and animals; capable to dye other substances such as textile material, leather, food, medicine etc. This technique of dyeing was practiced by ancient people before thousands of years (Geelani et al., 2015).

Natural dyes fall into three categories on the basis of their origin: plant, animal and mineral (Jihad, 2014).

Natural dyes extract from a variety of the substance with are occur in nature such as plants (e.g., indigo and saffron); insects (e.g., cochineal beetles and lac scale insects); animals (e.g., some species of mollusks or shellfish); and minerals (e.g., ferrous sulfate, ochre, and clay) without any chemical treatment (Kadolph, 2009). Natural dyes are obtained from various sources. These dyes can be classified as: i. Plant sources -Berry, flower, bark, leaf, seed etc (e.g. catechu, Indigofera, myrobalan, pomegranate). ii. Insect sources - Cochineal and lac. iii. Animal sources - Mollusk, murex snail, cuttlefish and shellfish. iv. Mineral sourcesClay, ochre and malachite (Singh and Srivastava, 2015).

The main sources of natural dyes are classified as follows (Moses and Venkatachalen, 2001).

Vegetable dyes: In early times the plant world furnished the principal source of the dyestuffs by which one obtained colour. There were as many as 500 plant species identified as sources for dyes. These vegetable sources are not only replaceable but also bio-degradable.

They also have pharmaceutical and health benefit. They can be obtained from various parts of a plant like roots, stems, stalks, foliage, barks, berries and seeds (Sengupta, 2001; Patel and Karolia, 2005; Singh and Yadav, 2000). The content and the amount of the coloring materials in plants greatly vary with the harvest season as well as the age of the plants (Siva, 2007).

Animal dyes: Dyes are also obtained naturally from animals. The best red dyes known to the people of those early times were of animal origin and were used for various shades of red and purple. Secretion of insects and dried insect bodies are the major source of natural dyes (Qicheng et al., 2003).

Leaccifer lacca: Lac is the oldest animal red dye known to man which is obtained from the resinous secretion of tiny insects Leaccifer lacca. 
Coccus ilicis: Kermes insects supplied the scarlet dyestuff which was used throughout ancient and medieval time.

Coccus cacti: The cochineal insect was brought to Europe by the Spanish in the early sixteenth century after the discovery of America. It gives shades of pink, purplish-red, grayish violet, scarlet.

Murex species: Two species of this class are the murex brandaris and the murex trunculus. The most highly prized ancient dyestuff, called 'Tyrian purple' obtained from the juices of certain species of avails found in the water of the Mediterranean sea.

\section{Mineral sources}

These are the dyes obtained from natural earth pigments, which owe their tinctorial properties due to the presence of oxides or the hydrated oxids of manganese. Example of mineral dyes are chrome yellow, iron buff, Prussian blue, nankin yellow and manganese brown etc.

They are very much insoluble in water and other solvents therefore the presence of binder is necessary to attack on the fiber surface. The colours obtained on the fiber are extremely resistant to light and chemical agencies and are modified to deeper and richer shades by calcinations. Many mineral colourants have been found to be poisonous in nature therefore, they have limited applications.

As minerals are used for fixing or improving the fastness of vegetable dye, the name natural dye is more appropriate which cover all the dyes derived from natural resources including vegetable dyes as well as minerals. And some minerals are also used to give a coloring matter. For example seru, cow urine, cow dung, egg albumin (Jihad, 2014).

\section{Application of natural dyes on textiles}

Nowadays use of natural materials and natural methods is considered to be an element that increases the value of a product and contributes to sustainable life in environmental, economic and sociologic senses (Dogan and Akan, 2018). Natural dyes consist of catechins, rosmarinic acid, flavonoids, carotenoids, ascorbic acid and anthocyanin groups in the structure, which show natural anti-oxidant property also. Natural dyes are mostly employed for dyeing of natural fiber textiles to enhance their ecofriendly characteristics. They are usually applied to textiles by dyeing. Apart from indigo, other natural dyes are usually not used for printing directly. Natural dyes, like synthetic dyes, can also be used to dye textiles at all stages such as fiber, yarn, or fabric.

Fiber dyeing has the advantage that any shade variation can be easily adjusted by blending and therefore has been practiced at industrial scale also but is costly due to problems in spinning and loss of dyed fibers. Wool is generally dyed in yarn form and traditional dyers prefer yarn dyeing for all materials as it offers versatility in designing during weaving. Dyeing is normally carried out by hand in large vessels. Iron, stainless steel, copper, and aluminum vessels are used. Dyeing in copper vessels is considered to produce bright shades. Aluminum vessels are normally stained with a particular dye hence should be used if only one type of dye is used. Stainless steel vessels are most preferred for the natural dyeing process. On a larger scale, hankdyeing machines have been successfully used (MIAH et al, 2016).

Natural fibres can successfully bond with natural dye. Mainly silk, wool, alpaca from animal origin and cotton, jute, linen from plant origin are considered as natural fibres. Animal fibres are protein based fibres which 
have strong affinity towards natural dye than plant based fibres (Ado et al., 2014).

Dyes are generally used in textile, paper, cosmetic, food, pharmaceutical and leather industries (Kumar et al., 2019). According to the literature, natural dyes such as Walnut shells (Mirjalili and Karimi, 2013), Onion shells (MIAH et al, 2016; Nurunnesa et al., 2018), Cassia singueana (Teklemedhin et al., 2018) Curcuma longa L. (Ibrahim et al., 2010), Senegalia catechu (Ansari et al., 2018), Butea monosperma (Daberao et al.,2016), Hibiscus Rosa Sinensis (Bose and Nag, 2012), Ziziphus jujuba Mill. (Chungkrang et al., 2018), Orange \& Lemon peels (Kumar and Dhinakaran, 2017), Quercus infectoria Oliv. (Shahid et al., 2012), Saraca asoca and Albizia lebbeck (Baliarsingh et al., 2012) and so forth produce pigments which have widespread applications in textile dyeing industries and represent probable alternative to synthetic dyes.

The leaves of Bordi (Ziziphus numularia) can be successfully used for dyeing of wool, cotton and silk with different natural and chemical mordants and obtained a wide range of soft, lusterous, pastel as well as bright colours (Rai and Sharma, 2001). Natural dye obtained from plants such as Black carrot, Hibiscus, Delonix, Plumeria, Combretum, Ixora, and Bischofia has been used for dying silk fabric (Shukla and Vankar, 2017).

The natural dye annatto is usually being recognized as Bixa orellana. It is a yelloworange dye obtained from the seeds of this plant. It has high biodegradability, low toxicity, and compatibility with the environment. Carotenoids, apocarotenoids, terpenes, terpenoids, sterols, and aliphatic compounds are main compounds found in all parts of this plant and are reported to exhibit a wide range of pharmacological activities. Annatto is used in solar cells, leather, food, textile and other industries (Shahid-ul-Islam et al., 2016).

In addition to their biodegradability and compatibility with the environment, natural dyes have been recently discovered to exhibit other functional properties such as antimicrobial activity (Khan et al., 2012; Shahid et al., 2013), anti-fungal, anti-viral activity (Gupta et al., 2004), insect repellent (Ali et al., 2013), UV protection (Sun and Tang, 2011) and deodorizing agents (Lee et al., 2009). The cosmetic industry now employs many natural dyes due to the fact they will cause fewer side affect than the employment of synthetic dyestuffs but they can also provide extra properties such as UV protection, skin moisturizing and anti-aging (Chengaiah et al., 2010). Antibacterial finishes can have potential benefits to contain the spread of disease, avoid the danger of injury-induced infection, and prevent the deterioration of textiles and have other advantages (Gao and Cranston 2008). As it is evident from the increase of scholarly and popular literature about natural dyeing, the interest in natural dyes today is growing even in countries where the use of natural dyes is no more than history. It's caused by a general environmental awareness and the increase of public interest in natural products. Today natural dyes have a variety of applications. They are used not only in textile dyeing and functional finishing (antimicrobial, antifeedant, deodorising or UV protective), but also as food and cosmetic colourants, cosmetic healing additives, $\mathrm{pH}$ indicators and in several other uses (Carvalho and Santos, 2016).

In conclusion the natural colouring substances are now developing trends for their use all over the world because of health hazards and toxicity problems created by the synthetic dyes (Phukon, 2010). There are many research works that has been carried out by 
many researchers/scientists belonging to industry, small and medium entrepreneurs, social organizations (NGO's), Government organizations, researchers in various educational institutes and research organizations etc. on the revival of natural dyes for the colouration of textiles. Through this review collected on natural dyes, it is attempted to explore the available sources of natural dyes and its utilization in textiles.

\section{References}

Ado, A., Yahaya, H., Kwalli, A. A. and Abdulkadir, R. S. (2014). Dyeing of textiles with eco-friendly natural dyes: A review. International Journal of Environmental Monitoring and Protection, 1(5): 76-81.

Akkewar, D.M. (1999). National colour of commercial importance. Convention on Natural Dyes. $9-11^{\text {th }}$ December, Department of Textiles Technology, IIT, Delhi. p. 132.

Ali, M.A., Almahy, H.A. and Band, A.A.A. (2013). Extraction of carotenoids as natural dyes from the Daucus carota Linn (carrot) using ultrasound in Kingdom of Saudi Arabia. Research Journal of Chemical Sciences, 31: 6366.

Ansari, T. N., Iqbal, S. and Barhanpurkar, S. (2018). Ecofriendly Dyeing with Senegalia catechu Using Biomordant. International Journal of Creative Research Thoughts, 6(1): 1351-1354.

Arora, J., Agarwal, P. and Gupta, G. (2017). Rainbow of Natural Dyes on Textiles Using Plants Extracts: Sustainable and Eco-Friendly Processes. Green and Sustainable Chemistry, 7: 35-47.

Baliarsingh, S., Panda, A.K., Jena, J., Das, T. and Das, N.B. (2012). Exploring sustainable technique on natural dye extraction from native plants for textile: identification of colourants, colourimetric analysis of dyed yarns and their antimicrobial evaluation. Journal of Cleaner Production, 37: 257-264.

Bansal, A. and Sood, A. (2006). Dyeing of silken yarns with Berberry dye. Tex. Trends, XLVIII (12): 39-42.

Bhuyan, R. and Saikia, D.C. (2004). Natural dyes: Present scenario in North East India. Colourage LI (5): 27-32.

Bose, S. and Nag, S. (2012). Isolation of Natural Dyes from the Flower of Hibiscus Rosa-Sinensis. American Journal of Pharm Tech Research, 2(3): 761-770.

Carvalho, C. and Santos G. (2016). Sustainability and Biotechnology Natural or Bio Dyes Resources in Textiles. Journal of Textile Science \& Engineering, 6(1): 1-5.

Chavan, R.B. (1995). Revival of natural dyes - A word to caution to environmentalists. Colourage 42(4): 2730 .

Chengaiah, B., Rao, M. K., Kumar, M.K., Alagusundaram, M. and Chetty, M. C. (2010). Medical importance of natural dyes - A review. International Journal of PharmTech Research, 2 (1): 144-154.

Chungkrang, L., Phukan, A.R. and Kalita, B.(2018). Eco-dyeing of wool yarn with Ziziphus jujuba Mill. (Ber) and its colour fastness properties. Journal of Applied and Natural Science, 10 (3): 1046 - 1052.

Daberao, A. M., Kolte, P. P. and Turukmane, R. N. (2016). Cotton Dying with Natural Dye. International Journal of Research and Scientific Innovation, 3(8): 157-161.

Darwekar, M., Gorpade, B. and Vankar, P.S. (1999). Microwave assisted improved synthesis of indigoid dyes and anthaquinoid dyes, indigo, yellow 3G, tyrian blue, alizarin, orange and alizarin blue. Convention on Natural Dyes. 9$11^{\text {th }}$ December, Department of Textiles 
Technology, IIT, Delhi. p. 132.

Dogan, S.D. and Akan, M. (2018). A Research on Colours and Fastness Values of Different Materials Dyed with Some Natural Dyes. International Journal of Materials Science and Applications, 7(3): 69-74.

Gao, Y. and Cranston, R. (2008). Recent advances in antimicrobial treatments of textiles. Textile Research Journal, 78,(1) :60-72.

Geelani, S. M., Ara, S., Mir, N. A., Bhat, S. J. and Mishra, P. K. (2016). Dyeing and fastness properties of Quercus robur with natural mordants on natural fibre. Textiles and Clothing Sustainability, 2(8): 2-10.

Geelani, S. M., Ara, S., Mishra, P. K., Bhat, S.J.A., Hanifa, S., Haq, S., Jeelani, I., Qazi, G., Sofi, A. H., Mir, S. A., Khan, P.A., Wani, S. A. and Raja, A.S.M. (2015). Ecofriendly dyeing of wool and pashmina fabric using Quercus robur L. (fruit cups) dye and Salix alba L. (wood extract) mordant. Journal of Applied and Natural Science, 7(1) : 138 - 143.

Gowda, K.N.N. and Sudhha, R. (2001). Dyeing of silk with areca catechu waste. In conventional proceedings natural dyes. Department of Textile Technology, December 17-18, IIT, Delhi. pp. 132-133.

Guha, A.R. (2019). A Review on Sources and Application of Natural Dyes in Textiles. International Journal of Textile Science, 8(2): 38-40.

Gulrajani, M.L. (1999). Present status of natural dyes. Colourage, 46(7): 19-28.

Gulrajani, M.L. (2001). Technology for production and application of natural dyes on textiles. In conventional proceedings natural dyes. Department of Textile Technology, December 17-18, IIT, Delhi. pp. 3-9.

Gupta, D., Khare, S.K. and Laha, A. (2004). Antimicrobial properties of natural dyes against Gram-negative bacteria. Coloration Technology, 120 (4): 167171.

Gupta, D.R. (1990). Substitute of harda as mordant - a study. Text. Dyer Printer 23(10): 21-23.

Ibrahim, N.A., El-Gamal, A.R., Gouda, M. and Mahrous, F. (2010). A new approach for natural dyeing and functional finishing of cotton cellulose. Carbohydrate Polymers, 82(4): 12051211.

Islam, S., Rather, L.J., Shahid, M., Khan, M.A. and Mohammad, F. (2014). Study the effects of ammonia post-treatment on color characteristics of annatto-dyed textile substrate using reflectance spectrophotometer. Industrial Crops and Products, 59: 337-342.

Jihad, R. (2014). Dyeing of Silk Using Natural Dyes Extracted From Local Plants. International Journal of Scientific \& Engineering Research, 5 (11): 809-818.

Kadolph, J. (2009). Textiles $10^{\text {th }}$ Edition, Dorling Kindersley (India) Pvt. Ltd. Licenses of Pearson Education in South Asia, pp. 41.

Kajla, A. and Srivastava, M. (2006). A comparative study on color development and fastness evaluation of Manjistha on polyester fabric and its blends. Textile Trends, XLVIX (8): 37-40.

Kerolia, A. and Dilliwar, S. (2004). Natural yellow dyes from marigold flowers for leather. Colourage, LI (6): 31-32.

Khan, M.A., Khan, M., Srivastava, P.K. and Mohammad, F. (2005). Extraction of natural dyes from Myrobalan, Gallnut and Pomegranate and their application on wool. Colourage, LII (12): 53-59.

Khan, S.A., Ahmad, A., Khan, M.I., Yusuf, M., Shahid, M., Manzoor, N. and Mohammad, F. (2012). Antimicrobial activity of wool yarn dyed with Rheum emodi L. (Indian Rhubarb). Dyes and 
Pigments, 95: 206-214.

Kumar, C. S. S. and Dhinakaran, M. (2017).

Extraction and Application of Natural Dyes From Orange Peel and Lemon Peel on Cotton Fabrics. International Research Journal of Engineering and Technology, 4(5): 237-238.

Kumar, P.E., Santhi, M. and Ananthakumar, S. (2019). A Study on the Extraction of ECO - Friendly Natural Dyes from Hibiscus Rosa Sinensis and Clitoria Ternatea for Dyeing. IOSR Journal of Polymer and Textile Engineering (IOSRJPTE), 6(2): 26-31.

Lee, Y., Hwang, E. and Kim, H. (2009). Colorimetic assay and antibacterial activity of cotton, silk and wool fabrics dyed with peony, pomegranate, clove, Coptis chinenis and gallnut extracts. Materials, 2: 10-21.

MIAH, M.R., Telegin, F.Y. and Rahman, M.R. (2016). Eco-friendly dyeing of Wool fabric using natural dye extracted from onion's outer shell by using water and organic solvents. International Research Journal of Engineering and Technology (IRJET), 03 (09): 451-467.

Mirjalili, M. and Karimi, L. (2013). Extraction and Characterization of Natural Dye from Green Walnut Shells and Its Use in Dyeing Polyamide: Focus on Antibacterial Properties. Journal of Chemistry, pp. 1-9.

Moses, J.J. and Venkatachalam, A. (2001). Natural dyeing on cellulosic and protein textile materials. In conventional proceedings natural dyes. Department of Textile Technology, December 17-18, IIT, Delhi. pp. 121-131.

Mukherjee, A., Maulik, S.R., Choudhurry, P.K. and Mitra, A. (2005). Application of natural dyes in Handloom Sectors. Textile Trends, XLVIII (3): 37-40.

Nurunnesa; Hossain, M. A. and Rahman, M. M. (2018). Extraction of Natural Dye Collected from Outer Skin of Onion and its Application on Silk Fabric. Global Journal of Researches in Engineering: J General Engineering, 18(3).

Patel, F. and Kerolia, A. (2005). Dyeing of cotton fabric with red sandalwood. Textile Trends, XLVIII (9): 45-48.

Paul, R., Malankir, J.V. and Naik, S.R. (1996). Natural dyes: Classification, extension and fastness properties. Textile Dyer Printers, 29(22): 16-24.

Phukon, R. (2010). Use of indigenous dyes for economic upliftment and sustainable livelihood. Asian J. Home Sci., 4 (2): 395-397.

Phukan, R., Phukan, A.R. and Ahmed, G.U. (2005). Dyeing of silk yarn with the heart wood of jack fruit. Textile Trends, XLVIII(7): 33-36.

Prabhu and Bhute, A. S. (2012). Plant based natural dyes and mordants: a review. Journal of Natural product and Plant Resource, 2(6) : 649-664.

Pruthi, N., Chawla, G.D. and Yadav, S. (2008). Dyeing of silk with barberry bark dye using mordant combination. Natural Product Radiance, 7(1): 40-44.

Qicheng, Z., Leu, W., Sunghee, K., Sunhua, J. and Menlong, C. (2003). Bio-dyes for wool. Textile Asia. pp. 46-48.

Rose, N.M., Khanna, S., Singh, S.S.J. and Gaba, G. (2005). Dyeing with natural colouring material - Geranium bark. Textile Trends, XLVIII (4): 45-47.

Samanta, A.K. and Agarwal, P. (2009). Application of natural dyes on textiles. Indian Journal of Fibre \& Textile Research, 34: 384-399.

Sengupta, S. (2001). Application of the liquor for colouration of cotton fabric. Textile Trends, XLIV (3): 21-23.

Shahid, M., Ahmad, A. and Yusuf, M. (2012). Dyeing, fastness and antimicrobial properties of woolen yarns dyed with gallnut (Quercus infectoria Oliv.) extracts. Dyes and Pigments, 95(1): 5361. 
Shahid, M., Shahid-ul-Islam and Mohammad, F. (2013). Recent advancements in natural dye applications: a review. Journal of Cleaner Production, 53: 310331.

Shahid-ul-Islam; Luqman, J. R. and Mohammad, F. (2016). Phytochemistry, biological activities and potential of annatto in natural colorant production for industrial applications - A review. Journal of Advanced Research, 7: 499514.

Shankar, R. and Vankar, P.S. (2005). Dyeing wool with Gampherna Globsa flower. Colourage LII (4): 35-37.

Shukla, D. and Vankar, P.S. (2017). Natural Dyes for Textiles, Sources, Chemistry and Applications. A volume in Woodhead Publishing Series in Textiles, pp. 141-166.

Singh, K. and Parmar, S.S. (1998). Are natural dyes safer than synthetic dyes? Textile Trends XL (11): 23-27.

Singh R. and Srivastava, S. (2015). Exploration of Flower Based Natural Dyes - A Review. Research Journal of Recent Sciences, 4(IVC-2015): 6-8.

Singh, S.S.J. and Yadav, S. (2000). Optimization of dyeing conditions for wool using berberry bark. Textile Trends XLIII (6): 39-40.

Singh, S.S.J., Yadav, S. and Gaba, G. (2001). Standardization of dyeing conditions for wool and cotton with Rein wardetia flowers dye. New Cloth Market, 15(5): 17-19.
Siva, R. (2007). Status of natural dyes and dye yielding plant in India. Current Science, 92(7): 916-925.

Sun, S.S. and Tang, R.C. (2011). Absorption and UV protection properties of the extract from honeysuckle onto wool. Industrial \& Engineering Chemistry Research, 50: 4217-4224.

Tasneem, K. and Maria, H. (2016). Isolation of natural dye from beet root and its application on wool and thread with different mordants at different temperatures. International Journal of Advances in Engineering \& Scientific Research, 3(1): 52-62.

Tekajev, A.T. (2003). The economic and ecologic principles of dyeing the wool fibers. Dyeing expert Turkmen Carpets Online.

Teklemedhin, T. B. and Gopalakrishnan, L. H. (2018). Environmental Friendly Dyeing of Silk Fabric with Natural Dye Extracted from Cassia singueana Plant. Journal of Textile Science \& Engineering, S3: 2-6.

Tripathi, G., Yadav, M.K., Padhyay, P. and Mishra, S. (2015). Natural dyes with future aspects in dyeing of Textiles: A research article. International Journal of Pharm Tech Research, 8 (1): 096-100.

Yusuf, M., Shabbir, M. and Mohammad, F. (2017). Natural Colorants: Historical, Processing and Sustainable Prospects. Nat Prod Bioprospect, 7(1): 123-145.

\section{How to cite this article:}

Lizamoni Chungkrang and Smita Bhuyan. 2020. Natural Dye Sources and its Applications in Textiles: A Brief Review. Int.J.Curr.Microbiol.App.Sci. 9(10): 261-269. doi: https://doi.org/10.20546/ijcmas.2020.910.034 